\title{
Automated telemedicine and diagnosis system (ATDS) in diagnosing ailments and prescribing drugs
}

\author{
Israa Al_Barazanchi ${ }^{1}$, Sawsan Ali Hamid ${ }^{2}$, Rana Alauldeen Abdulrahman ${ }^{3}$, Haider Rasheed \\ Abdulshaheed ${ }^{4}$ \\ ${ }^{1,4}$ Baghdad College of Economic Sciences University - Baghdad, Iraq \\ ${ }^{2}$ College of computer science, Tikrit university, Iraq \\ ${ }^{3}$ Department of Civil Technologies, Institute of Technology, Middle Technical University, Iraq
}

\section{Article Info}

Received Jan 15, 2019

\section{Keyword:}

Telemedicine, ATDS, Diagnosis, Ailment, Prescribing, Information Technology

\begin{abstract}
This paper presents an Automated Telemedicine and diagnosis system (ATDS), is an expert system that is used for diagnosing many ailments such as malaria and others. and prescription of drugs. ATDS is made up of knowledge database. The end user makes use of it to determine if they are suffering from one ailment or the by entering the ailment symptoms. Once the system receives the information from the user, an instant drug prescription and diagnosis is made. ATDS is user-friendly. However, ATDS was not developed to replace the real doctors but to assist patient waiting for human doctors that are few and to make the diagnosing and prescribing of drugs faster and more accurate. ATDS is implemented in PHP (Hypertext Preprocessor). Hospitals and other medical clinics should be readily accessible by everyone when needed as one of the many limitations of health care establishment is distance. ATDS when compared with old systems like MYCIN is more efficient in the different aspects. It solved the problem of incomplete base. ATDS proves efficiency more than another medical expert system by giving instant and correct ailment diagnosis and drug prescription.
\end{abstract}

\section{Corresponding Author:}

Israa Al_Barazanchi ${ }^{1}$, Computer science department,

Baghdad College of Economic Sciences University, Baghdad, Iraq https://orcid.org//0000-0002-6798-6295

Email: Israa44444@gmail.com

\section{Introduction}

The advent of information technology and communication has made it easier and possible for people to access proper medical diagnosis and prescription of drugs thus the emergence of need to use expert telemedicine system [1]. Telemedicine is health delivery and medical knowledge to people over a distance through different telecommunication means. Telemedicine simply means "healing at a distance". The World Health Organization (WHO, 1997) defined telemedicine as "The delivery of health care services, where distance is a critical factor, by all health care professionals using information and communication technologies for the exchange of valid information for diagnosis, treatment and prevention of disease and injuries, research and evaluation, and for the continuing education of health care providers, all in the interests of advancing the health of individuals and their communities" because there was no definite definition given to telemedicine $[2,3]$. An expert system makes use of knowledge and inference procedures in solving problems better and faster. These problems were ordinarily solved by human knowledge. Expert system is broken down into three major parts namely, the knowledge base, the inference engine, and user interface. It is very important that an expert system or AI that will assist medical services is developed and implemented. This calls for the immediate response in the development ATDS. ATDS is the solution to these problems, it brought the hospital and doctors at the fingertips of everyone. 


\section{Related works}

George Rosu and Eugene Roventa [3] enlarged a medical expert system for detecting major kidney diseases. The diagnosis is gotten from both clinic and Para clinical examination readings. This medical expert system assists physicians in making the correct and trusted analysis of a patient. Kidney disease has many common and similar symptoms that is hard for doctors to make correct diagnosis but with this system, the problem was eliminated. This medical expert system has good and detailed knowledge base. It has in its knowledge base, 27 diseases from 9 dissimilar categories.

W.Abdalla, K.Abdelhamied, S.Hafez, [4] developed a medical expert system to assist health employees that work in overcrowded clinics in Africa--Egypt to be precise to offer immediate and correct health judgment. This system has over 300 major and minor rampart diseases is its knowledge base that exists as production rules. These rules play a part in presenting diagnostic hypotheses and symptoms and diagnostic hypotheses of most expected diseases to match these symptoms. Recommendation is made when a disease is identified. Solomon Gebremariam [5] developed a self-learning system with prototype methodology that gives advice to both doctors and patients in helping and treating patients with diabetes. Knowledge is gotten from interviewstructured and unstructured and expert in the field of diabetes. It uses the backward chaining that predicts possible solutions to solve the problem. The performance of this self-learning expert system is 84.2 per cent.

\section{Overview of the proposed system (ATDS)}

\subsection{Adopted design and methodology}

Object-Oriented Analysis and Design is the design methodology used and the major programming language that was used in the design is PHP while MySQL was used as the database. The object-oriented technique gives a no interruption process that aid in the software architecture viewing in elements [6-8]. Object-oriented analysis and design models every system as a set of interacting objects. Every object describes some entity being modelled in the system and it is attributed by its class, behaviour and state [9-11]. ATDS was broken down into classes that handles different operations. The classes have both methods and attributes for achieving its target goals. UML diagrams (system flowchart and program flowchart) were used to represent the relationship between all the entities in ATDS. Figure1 shows the Program flowchart of ATDS while Figure 2 shows the System flowchart of ATDS.

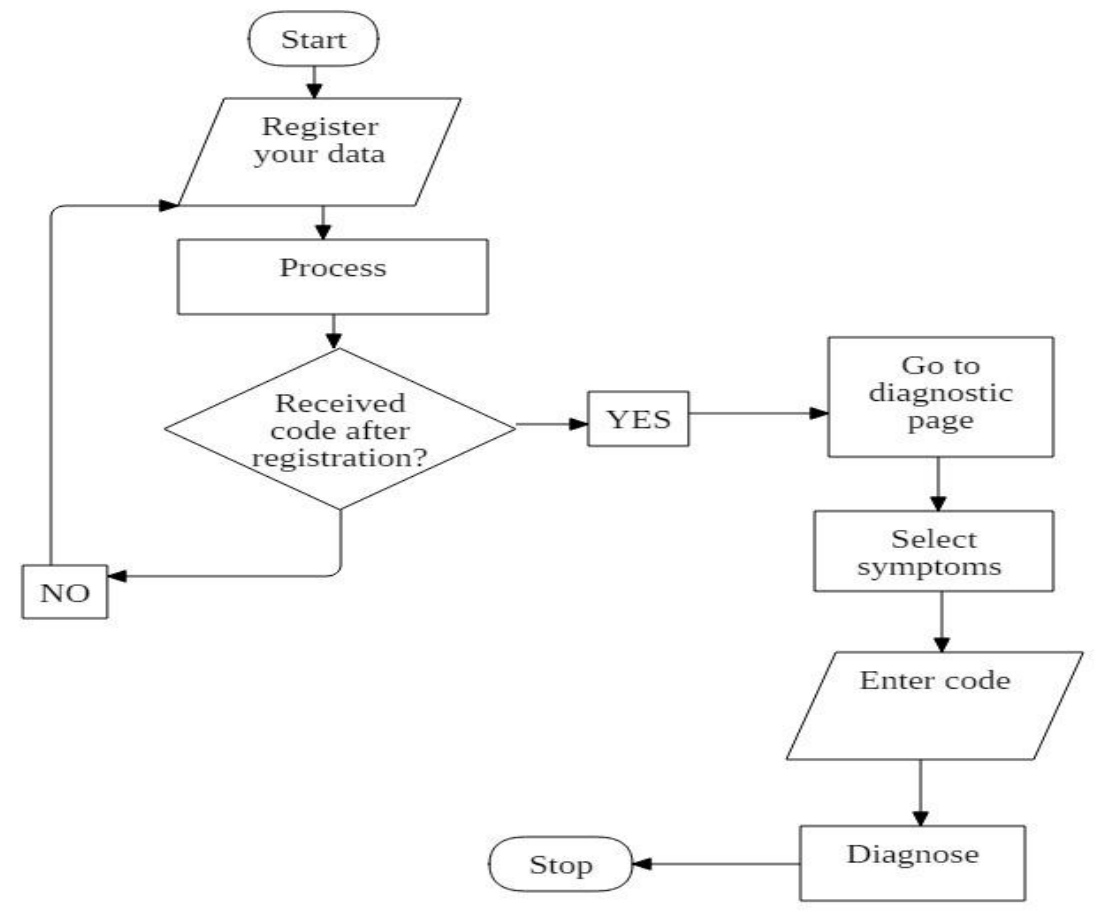

Figure 1. Program flowchart of ATDS 


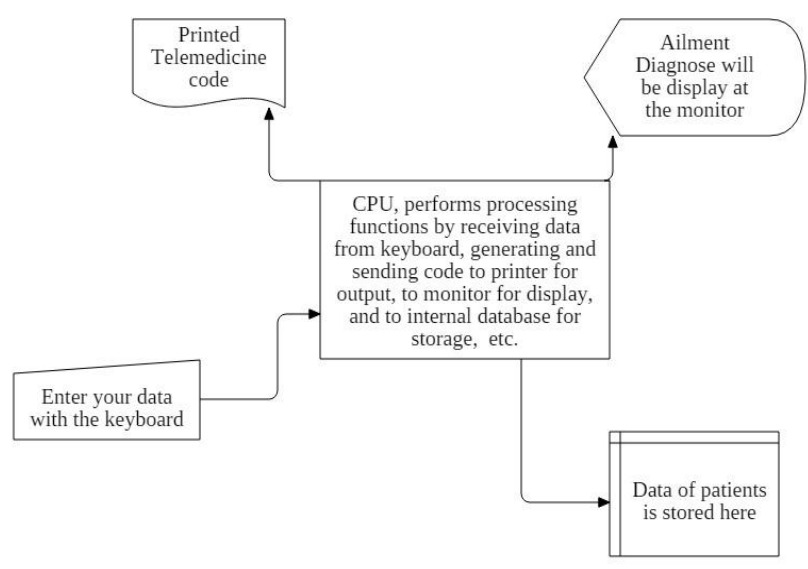

Figure 2. System flowchart of ATDS

\subsection{Components of ATDS}

ATDS is an expert system that uses artificial intelligence in diagnosing ailments such as Malaria, Hepatitis, Typhoid, Hypertension etc. the prescribing correct drugs needed to treat each ailment for patients. ATDS is user-friendly; it allows users/patients to enter the symptoms of the ailment. Once the system accepts patient's data in its database, an immediate information about the ailment and drug prescription for the ailment is made available instantly. ATDS is made up of the aforementioned three major parts of an expert system. The other parts of ATDS include the Human expert and Knowledge acquisition facility. The development environment used in ATDS are PHP which stands for Hypertext Pre-Processor, SQL that stands Structured Query Language HTML that stands for Hypertext Mark-up Language, JS that stands for Java Script and CSS that stands for Cascading Style Sheet. All of them have their functions.

\section{- Hardware requirement of ATDS}

ATDS makes use of the following hardware:

A PC system running on Pentium 4 or a higher processor.

A minimum of 512MB installed Random Access Memory.

An Enhanced Keyboard.

A mouse.

Colour Visual Display Unit.

An Inkjet Printer.

A DVD drives.

A modem to access internet or any other alternative.

- Software requirement of ATDS

The software requirement of ATDS include:

Windom XP (or a higher version).

MySQL software.

Anti-Virus protection software.

Web-based application software (HTML, CSS, JAVASCRIPT, PHP etc).

\subsection{How ATDS works}

The knowledge acquisition facility acquires valid information of both the ailments diagnosing and treatment. This valid information acquires by the knowledge acquisition facility kept in the knowledge base. The knowledge base was derived and built from different means such as journal, experienced medical practitioners. The rational database is where all this information or derived knowledge are stored. Manipulation of the information and knowledge is done by the inference engine. It does this by accepting queries from the patients or end user, processes the query. The interference engine also sends the right information after manipulation of the information entered by the end users with that of the knowledge base back via a user interface. ATDS uses a scripting language as its inference engine The Scripting language expresses both rules and facts associated with the ATDS. There is definition of a user-friendly user interface for the system to interaction with. The queries of end users are sent to ATDS for processing. The medical result or report gotten is sent back to the user through the interface. 


\subsection{Application of ATDS}

ATDS provides immediate and correct ailment diagnosis and drug prescription in regions or countries with low-income and limited infrastructure. ATDS is used as a faster and mobile hospital and doctor consultation over one ailment or the other. ATDS is used through the internet by people in both rural and urban areas to reduce the cost of medical care.

\subsection{Interface of the main menu}

The main menu is the set of interacting component parts that works together to meet a goal. It is through it that which other submenus could be accessed. The control centre main menu of this system includes the user's registration interface from which the telemedicine code is generated which serves as the authorized medium for obtaining the diagnosing of ailment and drug prescription. Diagnostic menu button on the index page is another main menu that opens a subsystem for the selection of ailment symptoms in order to receive their diagnosis and drug prescription. It is the page, that the generated telemedicine code will be used for obtaining the goal - diagnosis and drug prescription. Figure3 shows the main menu of ATDS.

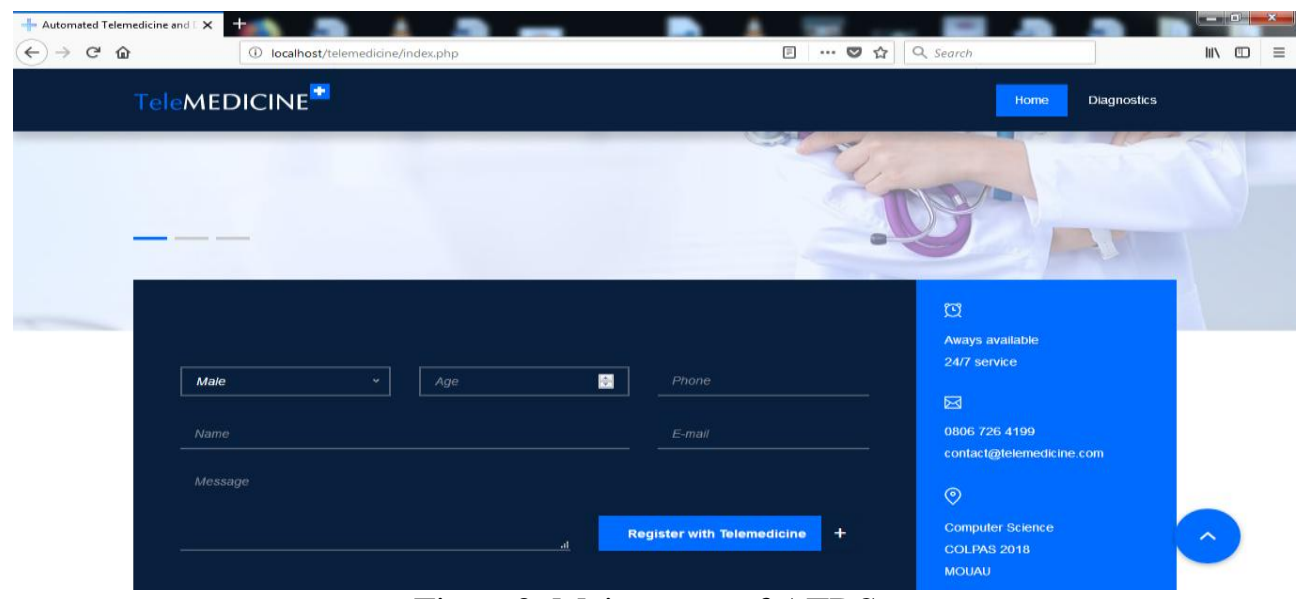

Figure3. Main menu of ATDS.

\section{Testing data}

The data used in achieving the testing plan are:

Input/output data: This is the test data that is accepted and processed to provide/produced the output that is compared with the expected output. Input data is also called the credentials of end users. The testing data are name, age, gender, email, symptoms, telemedicine code etc.

\subsection{Actual test result versus expected test result}

After carrying out a test with the user's input data - information details, telemedicine code and inputted symptoms of malarial - headache, fever, nausea chill, abdominal pain, the system diagnose the ailment to be malaria as expected. Table1 shows the result of using Test data.

Table1. Result of using Test data.

\begin{tabular}{|c|c|c|}
\hline Test data & Actual test result & Expected test result \\
\hline Headache, fever, nausea chill, abdominal pain. & Suspected malaria. & Malaria \\
\hline
\end{tabular}

\section{The comparation}

This part introduces the comparation of system currently used called MYCIN with the proposed system ATDS [12-15]. The MYCN uses artificial intelligence to find out bacteria that causes infections, like bacteria. MYCIN also recommend antibiotics to patients. It was writing in Lisp language under Bruce G. Buchanan, and others direction. The MYCIN system is made up of 3 subprograms namely the Consultation Program that interacts with the doctor to get patients information and to generate diagnoses and recommend treatment; the Explanation Program that offers both justifications and explanations for the actions of the program and the Knowledge-Acquisition Program for updating knowledge base of MYCIN. The inference engine and 
knowledge base are 2 major parts of MYCIN but also incorporates an explanation subsystem for explaining the system performance. However, MYCIN has some shortcomings which include [16-20]:

- Having incomplete knowledge base as not all infectious diseases are covered.

- As of its origin, many hospitals cannot afford it because more computing power for running it was required.

- The user interface was not good, and it was difficult for doctors to type at the terminal.

- It has slow response

On the other hand, ATDS knowledge acquisition facility acquires valid information of both the ailments diagnosing and treatment. This valid information acquires by the knowledge acquisition facility kept in the knowledge base. The knowledge base was derived and built from different means such as journal, experienced medical practitioners.

The rational database is where all this information or derived knowledge are stored. Manipulation of the information and knowledge is done by the inference engine. It does this by accepting queries from the patients or end user, processes the query. The interference engine also sends the right information after manipulation of the information entered by the end users with that of the knowledge base back via a user interface.

ATDS solve the limitations of MYCIN by:

- Providing instant and accurate ailment diagnosis and drug recommendation or prescription.

- The computation power is high that people in distance places can use it.

- Hospitals can afford it thus saving more lives.

- The user interface was designed to be very easy to use.

\section{Performance evaluation}

ATDS was tested by imputing data such as name, age and gender and phone number. The system responded immediately by outputting a telemedicine code to be used to access the symptoms page. After selecting symptoms and entering the telemedicine code, it predicted correctly the right ailment and drug prescription. After series of testing with different data the performance of ATDS was optimal.

\section{Limitation of ATDS}

Just like there is no perfect medical artificial intelligence or expert system, ATDS has limitations too though not much like other medical expert system [21-26]. ATDS does not diagnose and prescribe all ailment but only malaria, typhoid, fever, and hypertension. So, it is not to be used for all ailments. ATDS will only work for you when you have internet data connection. ATDS though an expert system will only give you the correct result when you enter symptoms that matches its knowledge base for that ailment.

\section{Result}

The design and development of ATDS is an addition to diagnose ailments and restore health through drugs prescription. ATDS lowers the works done by physicians by granting patient self-diagnosis. In addition, other similar medical expert systems are created through the design of ATDS. ATDS proves efficiency more than another medical expert system by giving instant and correct ailment diagnosis and drug prescription. This is not so in others as either the show your multiple ailments closest to the symptoms or only provide the aliments without recommending the correct drugs. Lack of security and privacy is a major problem in other medical expert system but ATDS is very efficient in securing patients data and offers double authentication to achieve this. While many expert systems wait for a patient to finish before accessing it, ATDS is efficient because it supports multiple users at the same time. It runs on high computation rate than others that have low response rate.

\section{Conclusion and future works}

ATDS involves the giving of health care to patients by using internet, from anywhere and anytime. There is no need for the doctor and the patient to meet. The driving purpose ATDS was to provide immediate health care services at one's comfort and convenience. ATDS reduces the big cost common to patients who visit the hospital on regular basis. ATDS diagnosed ailment and instantly provide the correct diagnosis and drugs prescription. 
In future, ATDS will go beyond its scope and limitation by providing diagnosis and drug prescription to more ailments. ATDS is an advancing expert system in the real world.

\section{References}

[1] Marimuthu, K.P., Prasada, H.P.T., and Kumar, C.S.C., 2019. Finite element modelling to predict machining induced residual stresses in the end milling of hard to machine Ti6Al4V alloy, 7 (1), pp.1-11.

[2] Feng, Y., Vladareanu, L., Chen, Z., Jin, D., Mimouni, I., and Wang, H., 2019. Research on mechanical design of a multi-function finger rehabilitation robot, 7 (1), pp.356-360.

[3] Ulmane-ozolina, L., Jansone, A., Magazeina, I., and Barute, D., 2019. Technology enhanced learning in teachers ' professional development, 7 (1), pp.216-221.

[4] Eugena Roventa, George Rosu, "The Diagnosis of Some Kidney Diseases in a PROLOG Expert System", proceedings of the third international workshop on Soft Computing Applications IEEE.

[5] K. Abdelhamied, S. Hafez, W. Abdalla, H. Hiekal, A. Adel, “ A Rule - Based Expert System for Rapid Problem Solving in Crowded Outpatients Clinics in EGYPT", proceedings of the IEEE Engineering in Medicine \& Biology Society tenth Annual International Conference IEEE.

[6] Solomon Gebremariam, "A Self Learning Knowledge Based System for Diagnosis and Treatment of Diabetes",Master's thesis, Addis Ababa University, Ethiopi.

[7] Shibghatullah, A.S. and Barazanchi, I. Al, 2014. An Analysis of the Requirements for Efficient Protocols in WBAN. Journal of Telecommunication, Electronic and Computer Engineering, 6 (2), pp.19-22.

[8] Abdulshaheed, H.R., Binti, S.A., and Sadiq, I.I., 2018. Proposed a Smart Solutions Based-on Cloud Computing and Wireless Sensing. International Journal of Pure and Applied Mathematics, 119 (18), pp.427-449.

[9]Thomas F. Heston (August 1st 2018). Introductory Chapter: Making Health Care Smart, eHealth - Making Health Care Smarter, Thomas F. Heston, IntechOpen, DOI: 10.5772/intechopen.78993. Available from: https://www.intechopen.com/books/telehealth/an-analysis-of-telemedicine-experiences-and-services-inchile.

[10] Thomas F. Heston (December 14th 2018). Introductory Chapter: Telemedicine, Telehealth, Thomas F. Heston, IntechOpen, DOI: 10.5772/intechopen.82419. Available from: https://www.intechopen.com/books/ehealth-making-health-care-smarter/terminology-services-standardterminologies-to-control-medical-vocabulary-words-are-not-what-they-sa

[11] American Telemedicine Association. What is Telemedicine? Available from: https://s3.amazonaws.com/rdcms-

himss/files/production/public/HIMSSorg/Content/files/Line\%2016\%20-

\%20What\%20Is\%20Telemedicine.pdf. Accessed January 24, 2017

[12] El Miedany Y, El Gaafary M, Youssef S, et al. Toward electronic health recording: evaluation of electronic patient-reported outcome measures system for remote monitoring of early rheumatoid arthritis. J Rheumatol. 2016;43(12):2106-2112.

[13] American Telemedicine Association. What is Telemedicine? Available from: https://s3.amazonaws.com/rdcms-

himss/files/production/public/HIMSSorg/Content/files/Line\%2016\%20-

\%20What\%20Is\%20Telemedicine.pdf. Accessed January 24, 2017

[14] Aitken M and Lyle J. Patient adoption of mHealth: Use, evidence and remaining barriers to mainstream acceptance. IMS Institute for Healthcare Informatics; 2015. Available from: www.imshealth.com/files/ web/IMSH\%20Institute/Reports/Patient\%20Adoption\%20of\%20mHealth/IIHI_Patient_ _of_mHealth.pdf. Accessed January 25, 2017.

[15] Fox S, Duggan M. Pew Research Internet Project. Available from: http://www.pewinternet.org/2013/01/15/health-online-2013/. Accessed January 26, 2017.

[16] Misra S. NHS Health Apps Library closing amid questions about app security \& quality: what can we learn? iMedical Apps. Medpage Today. Available from: http://www.imedicalapps.com/2015/10/nhshealth-apps-library-closing-commentary/. Accessed January 25, 2017. 
[17] Philips collaborates with Accenture to create first proof of concept for delivering vital patient data via Google Glass 2013. Available from: https://newsroom.accenture.com/industries/communications/philipscollaborates-with-accenture-to-create-first-proof-of-concept-for-delivering-vital-patient-data-via-googleglass.htm. Accessed January 25, 2017.

[18] Department of Health and UK Trade \& Investment The UK: Your partner for digital health solutions. Department of Health and UK Trade \& Investment; 2015. Available from: https://www.gov.uk/government/publications/the-uk-your-partner-for-digital-health-solutions/the-ukyourpartner-for-digital-health-solutions. Accessed 26 January 2017

[19] Daniel Luna, Carlos Otero, María L. Gambarte and Julia Frangella (August 1st 2018). Terminology Services: Standard Terminologies to Control Medical Vocabulary.

[20] Holt TA, Fletcher E, Warren F, et al. Telephone triage systems in UK general practice: analysis of consultation duration during the index day in a pragmatic randomised controlled trial. $\mathrm{Br} \mathrm{J}$ Gen Pract. 2016;66(644): e214-e218.

[21] WHO. A health telematics policy in support of WHO's Health-For-All strategy for global health development: report of the WHO group consultation on health telematics, 11-16 December, Geneva, 1997. Geneva, World Health Organization, 1998.

[22] Text of the Telehealth Modernization Act of 2013. Available from: https://www.congress.gov/bill/114thcongress/house-bill/691/text?format=txt. Accessed January 25, $2017 .$.

[23] Antonio Rienzo Renato (January 21st 2019). An Analysis of Telemedicine Experiences and Services in Chile, Telehealth, Thomas F. Heston, IntechOpen, DOI: 10.5772/intechopen.81756. Available from: https://www.intechopen.com/books/telehealth/an-analysis-of-telemedicine-experiences-and-services-inchile.

[24] Marimuthu, K.P., Prasada, H.P.T., and Kumar, C.S.C., 2019. Finite element modelling to predict machining induced residual stresses in the end milling of hard to machine Ti6Al4V alloy. Periodicals of Engineering and Natural Sciences, 7 (1), pp.1-11.

[25] Vladareanu, L., Lile, R., Radulescu, M., Mitroi, D., and Marin, D., 2019. Intelligent control interfaces developed on Versatile Portable Intelligent Platform in order to improving autonomous navigation robots performances. Periodicals of Engineering and Natural Sciences, 7 (1), pp.324-329.

[26] Mackare, K. and Jansone, A., 2019. The concept for e-material creating and formatting application prototype. Periodicals of Engineering and Natural Sciences, 7 (1), pp.197-204. 